\title{
Synthesis and biological activity of raltitrexed-carrier conjugates
}

\author{
Monika Jagiello', Urszula Kanska', Dmitry Nevozhay' ${ }^{1}$ and Janusz Boratynski ${ }^{1,2} \bowtie$ \\ 1'Ludwik Hirszfeld Institute of Immunology and Experimental Therapy, Polish Academy of Sciences, Wroclaw, Poland; \\ 2). Dlugosz Academy, Czestochowa, Poland
}

Drugs used in chemotherapy give undesirable side effects, e.g., cardiotoxicity, leucopenia, hair loss and others. Covalent binding of a drug with a carrier may change its biodistribution, elimination and/or rate of transformation in the organism. The aim of this work was to synthesize conjugates of anticancer drug raltitrexed (RTX) with lysozyme, bovine serum albumin (BSA), and dextran T40 and to investigate their cytotoxicity and influence on the cell cycle in comparison with the free drug. Before conjugation RTX was transformed into anhydride by treatment with dicyclohexylcarbodiimide in dimethylformamide. Activated RTX was added into aqueous solution of carriers at different $\mathrm{pH}$ (from 8.5 to 10.5 ) for 3 to $15 \mathrm{~min}$. The reaction was stopped by reducing the $\mathrm{pH}$ to 7.0. Maximum yield of the reaction was obtained at pH 10 for BSA as well as for dextran. The highest level of substitution was obtained after $5 \mathrm{~min}$ of the reaction. In in vitro experiments on three cell lines: SW707, LoVo and A549, all conjugates tested had up to a few hundred times higher $I C_{50}$ than the free drug. Interestingly, it was noticed that the conjugates based on dextran and albumin were more cytotoxic than the free drug in the highest concentrations tested (1000 and $10000 \mathrm{ng} / \mathrm{ml}$ ). The influence of RTX and the conjugates on SW707 cell cycle was studied. RTX blocked the cell cycle mostly in the $G_{0}-G_{1}$ and $S$ phase and increased the percentage of apoptotic cells. Cells in the $\mathrm{G}_{2}-\mathrm{M}$ phase were not observed. The conjugates blocked the cell cycle in the $\mathrm{S}$ phase and decreased the percentage of cells in the $G_{0}-G_{1}$ phase.

Keywords: raltitrexed, tomudex, carrier, conjugate, thymidylate synthase

Received: 15 October, 2009; revised: 18 March, 2010; accepted: 20 March, 2010; available on-line: 22 March, 2010

\section{INTRODUCTION}

Paul Ehrlich (Silverstein, 1999) suggested as early as in 1900 that specific transport of drugs to the tumor by carriers might circumvent their limited specificity which is a major problem in cancer chemotherapy. The use of antibodies as carriers was for the first time tested experimentally on L1210 leukemia (Mathe et al., 1958) and clinically in malignant melanoma (Ghose et al., 1972).

Drugs used in chemotherapy exhibit undesirable side effects, e.g., cardiotoxicity, leucopenia, hair loss and others. Covalent binding of a drug with a carrier may change its biodistribution, elimination and/or rate of transformation in the organism. Thus, conjugation offers the possibility of designinig preparations with increased accumulation in target tissues and decreased side effects (Nevozhay et al., 2007).
One of the best charaterized anticancer drugs is methotrexate (MTX). MTX is folate antagonist used mostly in the therapy of acute lymphocytic leukemia in children. Many compounds have been used as MTX carriers: antibodies, fibrinogen (Kanska et al., 2005), albumin (Kratz, 2008), dextrans (Nevozhay et al., 2006a; 2006b), mannan (Budzynska et al., 2007), dendrimers (Klajnert \& Bryszewska, 2001; Myc et al., 2010) polyethylene glycol (Riebeseel et al., 2002; Yousefi et al., 2010), and others. From among all the carriers of MTX examined, albumin turned out to be the most promising one. Both albumin and a MTX-albumin conjugate with the level of substitution (s.l.) equal 1 showed high tumor accumulation rates in rat Walker-256 carcinoma (Stehle et al., 1997). MTX-albumin revealed a higher antitumor activity in comparison with free MTX in rats with Walker-256 carcinoma, rats with Dunning prostatic adenocarcinoma (R3327 HI), and in the case of some human xenograft tumors in nude mice models (Wunder et al., 1998; Stehle et al., 1999; Burger et al., 2001). In 2002 phase I of clinical trials of MTX-human serum albumin (HSA) was completed and the conjugate was then qualified for phase II. According to published data, in phase I trials involving 17 cancer patients, tumor responses were seen in 3 patients (Hartung et al., 1999). In phase II study, a combination of MTX-HSA with cisplatin turned out to be promising and showed antitumor activity against urothelial carcinomas with an acceptable toxicity profile (Bolling et al., 2006)

Also fibrinogen is a promising antitumor drug carrier. Fibrinogen is a component of stroma of many tumors. The deposits of fibrinogen result from the characteristic hyperpermeability of tumor microvasculature, which contributes to the local extravasation of plasma fibrinogen. In our experiments fibrinogen-MTX conjugates exhibited lower in vitro cytotoxicity compared to MTX alone, but a significantly higher in vivo antitumor activity in mice with P388 leukemia (Boratynski et al., 2000; Kanska et al., 2005).

The present paper concerns conjugates of raltitrexed (RTX, Tomudex ${ }^{\circledR}$ ), which also belongs to the group of antimetabolite drugs. RTX acts as a specific inhibitor of thymidylate synthase. Raltitrexed is a chemotherapy drug used as treatment for malignant neoplasm of colon, rectum and some other types of cancer (Wilson et al., 2009)

To date, no data on raltitrexed-carrier conjugates have been published. The aim of this work was to synthesize conjugates of RTX with lysozyme, bovine serum albumin (BSA), and dextran T40 and to investigate their cy-

$\triangle$ e-mail: borat@iitd.pan.wroc.pl

Abbreviations: BSA, bovine serum albumin; DCC, N,N'-dicyclohexylcarbodiimide; DMF, N,N-dimethylformamide; HSA, human serum albumin; IC50, inhibitory concentration 50\%; MTX, methotrexate; RTX, raltitrexed; s.l., level of substitution; TCA, trichloroacetic acid. 
totoxicity and influence on the cell cycle in comparison with the free drug.

\section{MATERIALS AND METHODS}

Conjugate synthesis and characterization. RTX was purified from Tomudex ${ }^{\circledR}$ (Astra Zeneca UK Ltd, Macclesfield, Cheshire, Great Britain) on a CM-cellulose column. Mannitol and phosphates were eluted with MilliQ water, RTX was eluted with $N$,N-dimethylformamide (DMF, Sigma-Aldrich Chemie GmbH, Steinheim, Germany). The drug after removing DMF under vacuum was stored at $-20{ }^{\circ} \mathrm{C}$. RTX was activated in DMF using N,N'-dicyclohexylcarbodiimide (DCC, Sigma-Aldrich Chemie GmbH, Steinheim, Germany) before coupling with carriers. The concentration of RTX $(\mathrm{mg} / \mathrm{ml})$ was calculated by multiplying the absorbance in $0.1 \mathrm{M}$ dipotassium phosphate at $350 \mathrm{~nm}$ by 17.3. The molar ratio of RTX to DCC was 1:0.9. The reaction was carried out for $48 \mathrm{~h}$ in the dark at $4{ }^{\circ} \mathrm{C}$. A by-product, dicyclohexylurea, was removed by ultrafiltration. The obtained RTX anhydride in DMF was added under the surface of a stirred solution of a carrier: BSA (Sigma-Aldrich Chemie GmbH, Steinheim, Germany), lysozyme (SigmaAldrich Chemie GmbH, Steinheim, Germany ) or dextran T40 (Pharmacia, Uppsala, Sweden). The coupling reaction was carried out for $5 \mathrm{~min}$ in $0.02 \mathrm{M}$ phosphate buffer, $\mathrm{pH} 10$. Then the $\mathrm{pH}$ of the reaction mixture was reduced to 7 using $0.2 \mathrm{M}$ monopotassium phosphate. The obtained conjugates were purified on a Sephadex G25 (Loba Chemie, Wien-Fischamend, Austria) column using $0.05 \mathrm{M}$ phosphate buffer, $\mathrm{pH}$ 7.0, as an eluent. Pure conjugates were lyophilized and stored at $-20^{\circ} \mathrm{C}$.

Determination of substitution level of RTX conjugates. UV spectra of RTX in $0.1 \mathrm{M}$ aqueous $\mathrm{K}_{2} \mathrm{HPO}_{4}$ were collected $\lambda_{\max }: 350 \mathrm{~nm}\left(17100 \mathrm{M}^{-1} \mathrm{~cm}^{-1}\right)$ (in methanol $\left.\lambda_{\max }: 342 \mathrm{~nm}\left(1100 \mathrm{M}^{-1} \mathrm{~cm}^{-1}\right)\right)$. Protein concentrations $\left(\mathrm{mol} \mathrm{dm} \mathrm{dm}^{-3}\right.$ ) in RTX conjugates were determined from the following equations: $1.4\left(\mathrm{~A}_{280}-0.24 \mathrm{~A}_{350}\right) /$ $\mathrm{MW}_{(\mathrm{BSA})}$ (for BSA) and $1.22\left(\mathrm{~A}_{280}-0.24 \mathrm{~A}_{350}\right) / \mathrm{MW}_{\text {(lysozyme) }}$ (for lysozyme). The substitution level $\left(\mathrm{mol}_{\mathrm{RTX}} / \mathrm{mol}_{\text {protein }}\right)$ and RTX content $\left(\mathrm{mg}_{\mathrm{RTX}} / \mathrm{mg}\right.$ of conjugate) were calculated from the results of spectrophotometric measurements. In the case of dextran conjugates the substitution levels were assessed on the basis of determined weight content. Dextran content was determined by the phenolacetone method (Boratynski, 1984). The stability of the conjugates was examined using gel filtration on Sephadex G25. The influence of $\mathrm{pH}$ and temperature of storage was studied.

Cell lines. The following lines of cancer cells were used: A549 (human non-small cell lung carcinoma), SW707 (human colon adenocarcinoma), LoVo (human colon carcinoma). All lines were obtained from the American Type Culture Collection (Rockville, Maryland, USA) and are maintained in culture or frozen at the Cell Culture Collection of the Institute of Immunology and Experimental Therapy (Wroclaw, Poland).

Antiproliferative assay in vitro. Twenty-four hours before addition of the tested agents, the cells were plated in 96-well plates at a density of $1 \times 10^{4}$ cells per well and cultured in a mixture of RPMI 1640 and Opti-MEM (1:1) medium at $37^{\circ} \mathrm{C}$ in a humid atmosphere saturated with $5 \% \mathrm{CO}_{2}$. The cytotoxicity assay was performed after 72-hour exposure of the cultured cells to varying concentrations of the tested agents (from 1 to $10000 \mathrm{ng}$ of RTX/ml). In the case of adherent cells (A549, SW707 and LoVo), the in vitro cytotoxic effect of the agents tested was examined using the SRB assay (Skehan et al., 1990). Briefly, the cells were attached to the bottom of plastic wells by fixing them with cold 50\% trichloroacetic acid (TCA, Sigma-Aldrich Chemie GmbH, Steinheim, Germany). The plates were incubated at $4{ }^{\circ} \mathrm{C}$ for one hour and then washed five times with tap water. The background optical density was measured in the wells filled with culture medium, without the cells. The cellular material fixed with TCA was stained for $30 \mathrm{~min}$ with $0.4 \%$ sulforhodamine B (Sigma-Aldrich Chemie Gmbh, Steinheim, Germany) dissolved in 1\% acetic acid (POCH, Gliwice, Poland). Unbound dye was removed by rinsing $(4 \times)$ with $1 \%$ acetic acid. The protein-bound dye was extracted with $10 \mathrm{mM}$ unbuffered Tris base (POCH, Gliwice, Poland) for determination of optical density (at $540 \mathrm{~nm}$ ) in a computer-interfaced, 96-well microtiter plate reader Multiskan RC photometer (Labsystems, Helsinki, Finland).

The results were calculated as an $\mathrm{IC}_{50}$ (inhibitory concentration $50 \%$ ) - the concentration which inhibits proliferation rate of the tumor cells by $50 \%$ compared to control solvent-treated cells. The $\mathrm{IC}_{50}$ values were calculated separately for each experiment. Each compound in every concentration was tested in triplicates in a single experiment, and each experiment was repeated three times.

Cell cycle analysis. The SW707 cells were plated in 6 -well plates at a density of $2 \times 10^{5}$ cells per well. After $24 \mathrm{~h}$ of incubation, the cells were exposed to varying concentrations of the agents tested. After a further $72 \mathrm{~h}$, the cells were harvested, washed in PBS and suspended in $70 \%$ ethanol for $24 \mathrm{~h}$ at $-18^{\circ} \mathrm{C}$. Then, the cells were washed twice in PBS, incubated with RNase $(8 \mu \mathrm{g} / \mathrm{ml})$ (Sigma-Aldrich Chemie GmbH, Steinheim, Germany) for $1 \mathrm{~h}$ at $37^{\circ} \mathrm{C}$ and stained with propidium iodide $(0.5 \mathrm{mg} /$ $\mathrm{ml}$ ) (Sigma Chemical Co., St. Louis, USA) for $30 \mathrm{~min}$ at $4{ }^{\circ} \mathrm{C}$. The cellular DNA content was determined using a FACS Calibur flow cytometer (Becton Dickinson, San Jose, CA, USA).

Antitumor activity assay in vivo. Sixteen-week-old $\mathrm{DBA} / 2$ and $(\mathrm{C} 57 \mathrm{Bl} / 6 \times \mathrm{DBA} / 2) \mathrm{F} 1$ mice were inoculated with $10^{6}$ leukemia (P388) cells i.p. RTX was administered to mice $24 \mathrm{~h}$ after tumor inoculation at doses: $0.1 ; 1,10$ or $40 \mathrm{mg} / \mathrm{kg}$. The increase in the life span of treated mice over the control (ILS\%) was calculated from the following formula: $\left(\mathrm{AST}_{\mathrm{T}} / \mathrm{AST}_{\mathrm{C}}\right) \times 100-100 \%$, where $\mathrm{AST}_{\mathrm{T}}$ is the average survival time of treated animals, and $\mathrm{AST}_{\mathrm{C}}$ is the average survival time of solvent-treated control mice.

Statistical evaluation. For experiments concerning the influence of the preparations tested on the cell cycle statistical analysis was performed by Kruskal-Wallis test. $P$ values lower than 0.05 were considered significant. Statistical analysis of results of antiproliferative assays was performed by ANOVA test. $P$ values lower than 0.001 were considered significant.

\section{RESULTS AND DISCUSSION}

One goal of the present study was to obtain conjugates of RTX with albumin, lysozyme or dextran T40. To optimize the conditions, the reaction of the activated drug with BSA or dextran T40 was carried out at different $\mathrm{pH}$ (from 8.5 to 10.5) and for different times (from 3 to $15 \mathrm{~min}$ ). The reactions of carboxylic groups with amino and hydroxyl groups run more efficiently at an alkaline $\mathrm{pH}$ because of deprotonation of the latter groups. The reaction was stopped by reducing the $\mathrm{pH}$ 
Table 1. Influence of pH and time of reaction of RTX anhydride with BSA and dextran T40 on the level of substitution

\begin{tabular}{lllllll}
\hline \multirow{2}{*}{ Sample } & $\begin{array}{l}\text { Reaction } \\
\text { time }(\mathrm{min})\end{array}$ & \multicolumn{5}{l}{ Level of substitution (mol RTX/mol carrier) } \\
\cline { 3 - 7 } & $\mathrm{pH} \mathrm{8.5}$ & $\mathrm{pH} \mathrm{9.0}$ & $\mathrm{pH} \mathrm{9.5}$ & $\mathrm{pH} \mathrm{10.0}$ & $\mathrm{pH} \mathrm{10.5}$ \\
\hline BSA + RTX & 3 & 0.28 & 0.29 & 0.29 & 0.31 & 0.30 \\
BSA + RTX & 5 & 0.31 & 0.33 & 0.34 & 0.38 & 0.31 \\
T40 + RTX & 3 & 2.64 & 2.74 & 2.88 & 3.19 & 3.02 \\
T40 + RTX & 5 & 3.03 & 3.07 & 3.20 & 3.51 & 3.36 \\
T40 + RTX & 15 & 1.05 & 1.15 & 1.20 & 1.68 & 1.46 \\
\hline
\end{tabular}

to 7.0. The maximum yield of the reaction was obtained at $\mathrm{pH} 10$ for BSA as well as for dextran (Table 1). The determination of reaction duration was especially important in the case of RTX-dextran conjugates because of the instability of the forming ester bond at an alkaline $\mathrm{pH}$. The highest level of substitution was obtained after 5 min of the reaction (3.51 moles of RTX/mole of dextran T40). After $15 \mathrm{~min}$ of the reaction the level of substitution was lower and amounted to 1.68 moles of RTX/mole of dextran T40. In the case of BSA the level of substitution obtained after $5 \mathrm{~min}$ at $\mathrm{pH} 10$ was 0.378 moles of $\mathrm{RTX} / \mathrm{mol}$ of BSA. In scaled up experiments these optimum conditions ( $5 \mathrm{~min}$ at $\mathrm{pH} 10$ ) were followed. Various substitution levels were achieved by varying the ratios of the reagents (Table 2). The conjugates were purified using gel filtration on a Sephadex G25 column.

To assess the reaction efficiency the conjugates were obtained at different molar ratios of RTX anhydride to the carriers and levels of substitution were determined. The yield of the reaction was $5-15 \%$ and $25-35 \%$ for dextran and albumin conjugates, respectively. In the case of lysozyme conjugates, very low levels of substitution were achieved (0.042 mole of RTX/mole of lysozyme). It could be explained by a higher protonation of the amino groups in lysozyme, which is a basic protein, in comparison with an acidic protein, albumin. Deprotonation of the amino groups is essential for efficient reac- tion. After separation of the conjugate from the free drug on Sephadex $\mathrm{G} 25$, the conjugate was subjected to ion-exchange chromatography on CM-cellulose (Fig. 1) to remove unbound lysozyme. Three fractions were observed: conjugate with the average substitution level of 1.4 , conjugate with the average substitution level of 0.37 and free protein. The first fraction was used for further studies.

The stability of the conjugates was studied. The conjugates dissolved in phosphate buffer, $\mathrm{pH} 7.0$, were stored at $-20^{\circ} \mathrm{C}$. After 21 days, $15.7 \%$ and $5.7 \%$ of free drug was released from the dextran-RTX and BSA-RTX conjugates, respectively. Decomposition was higher at $\mathrm{pH} 5.0$ and 9.0. The conjugates were the most stable when stored in lyophilized form at $-20^{\circ} \mathrm{C}$. In the case of the RTX-dextran conjugates the release of RTX was $5 \%$ and for the RTX-BSA conjugates we did not observe drug release.

The activities of RTX and the conjugates were tested in vitro on three cell lines: SW707, LoVo and A549. The results of in vitro experiments are summarized in $\mathrm{Ta}$ ble 2 . The cytotoxicity studies did not reveal any statistically significant differences between RTX, tomudex and medley of the RTX with carrier. All tested conjugates had up to a few hundred times higher $\mathrm{IC}_{50}$ than the free drug and therefore had lower in vitro cytotoxic activity $(P<0.001$ in all comparison tests). The cytotoxicity of the conjugates increased with increasing substitution level. A lower cytotoxic activity of conjugates compared to a free drug in standard cytotoxicity tests is a common result and does not implicate lower antitumor activity in vivo (Boratynski et al., 2000, Riebeseel et al., 2002; Kanska et al., 2005).

Interestingly, it was noticed that the conjugates based on dextran or albumin were more cytotoxic than the free drug in the highest concentrations tested (1000 and $10000 \mathrm{ng} / \mathrm{ml})$. The conjugates inhibited cell proliferation by about $90 \%$, whereas RTX in the same concentration inhibited it by no more than $65 \%$ (not shown).

Table 2. Cytotoxic activity in vitro of different conjugates of raltitrexed in comparison with free drug and the medley of the drug and the carrier

\begin{tabular}{lcccc}
\hline \multirow{2}{*}{ Compound } & \multicolumn{3}{c}{ IC $_{50} \mathrm{ng} / \mathrm{ml}^{\mathrm{a}} \pm$ S.D. } \\
\cline { 2 - 5 } & SW707 & LoVo & A549 & P388 \\
\hline RTX & $4.33 \pm 2.98$ & $1.85 \pm 0.71$ & $17.08 \pm 5.10$ & $0.57 \pm 0.10$ \\
Tomudex & $5.26 \pm 1.38$ & $3.21 \pm 0.68$ & $26.43 \pm 9.29$ & $0.99 \pm 0.07$ \\
RTX + carrier & $6.42 \pm 0.71$ & $4.51 \pm 0.48$ & $25.23 \pm 9.56$ & NT \\
RTX-dextran T40 (s.l. 8.75)b & $262 \pm 182$ & $83 \pm 5.8$ & $2620 \pm 1350$ & NT \\
RTX-dextran T40 (s.l. 1.50)b & $654.4 \pm 124.48$ & NT & NT \\
RTX-dextran T40 (s.l. 0.75)b & $773 \pm 165$ & NT & $6004 \pm 1212$ & NT \\
RTX-dextran T40 (s.l. 0.1)b & $3010 \pm 322$ & NT & NT \\
RTX-BSA (s.l. 1.13) & $820 \pm 126$ & NT & $3674 \pm 880$ & NT \\
RTX-BSA (s.l. 1.06) & $838 \pm 86$ & NT & $3736 \pm 1030$ & NT \\
RTX-BSA (s.l. 0.73) & $1334 \pm 258$ & $719 \pm 15$ & NT & NT \\
RTX-BSA (s.l. 0.66) & $1301 \pm 156$ & NT & NT \\
RTX-lysozyme & $102 \pm 20$ & $101 \pm 59$ & $3480 \pm 1340$ & NT \\
\hline
\end{tabular}

${ }^{a} C_{50}$ expressed in ng of RTX (either free or conjugated). ${ }^{b}$ Conjugates of s.l. 8.75, 1.50, 0.75 and 0.1 were obtained by using RTX anhydride to dextran ratio of $20,5.5,3.0$ and 0.7 , respectively. 

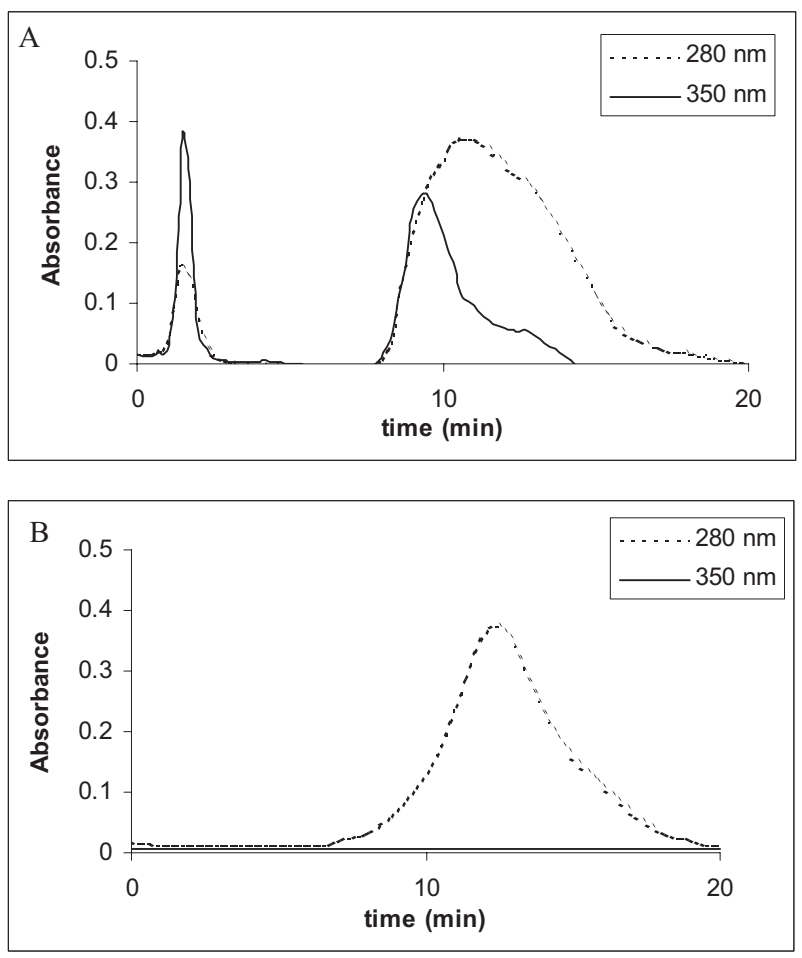

Figure 1. lon-exchange chromatography of RTX-lysozyme conjugate $(A)$ and lysozyme (B) as control.

Column: CM-cellulose (volume $1.1 \mathrm{~cm}^{3}$ ); eluent $\mathrm{A}$ : $0.01 \mathrm{M}$ phosphate buffer, pH 7.2; eluent B: $0.5 \mathrm{M}$ phosphate buffer, $\mathrm{pH}$ 7.2; flow: $0.3 \mathrm{ml} / \mathrm{min}$.

In the case of the RTX-lysozyme conjugate the cytotoxicity of RTX and the conjugate were comparable and the percentage of proliferation inhibition was $60-65 \%$. This could be connected with the low molecular mass of lysozyme $(14.6 \mathrm{kDa})$ and its polycationic character. The lack of a total proliferation inhibition could be connected with the presence of folic acid in the culture medium. Folic acid could compete with RTX for transport through the cell membrane and for the binding site of thymidylate synthase.

The influence of RTX and the conjugates on SW707 cell cycle was studied. The following conjugates were examined: RTX-dextran T40 (s.l. 1.5), RTX-BSA (s.l. 1.13) and RTX-lysozyme (s.l. 1.4). The concentrations of preparations were selected as approximate $\mathrm{IC}_{20}$ doses to give moderate inhibition of cell proliferation and avoid a high percentage of apoptotic cells. Albumin or lysozyme alone did not influence the cell cycle. In the case of dextran T40, the percentage of cells in $G_{2}-M$ was lower compared to control cells $(P<0.05)$. It was observed that conjugates influenced the cell cycle in a different way than the free drug. RTX blocked the cell cycle mostly in the $G_{0}-G_{1}$ and $S$ phase and increased the percentage of apoptotic cells. Cells in the $G_{2}-M$ phase were not observed. The conjugates blocked the cell cycle in the $\mathrm{S}$ phase and decreased the percentage of cells in the $G_{0}-G_{1}$ phase. There were no statistically significant differences between the percentages of cells in a given phase treated with different conjugates.

The in vivo activity of RTX and the RTX-BSA conjugates was examined on P338 murine leukemia model. In a preliminary experiment the drug was administered in a single dose from 0.1 to $40 \mathrm{mg} / \mathrm{kg}$. Even the highest dose was ineffective and did not increase the life
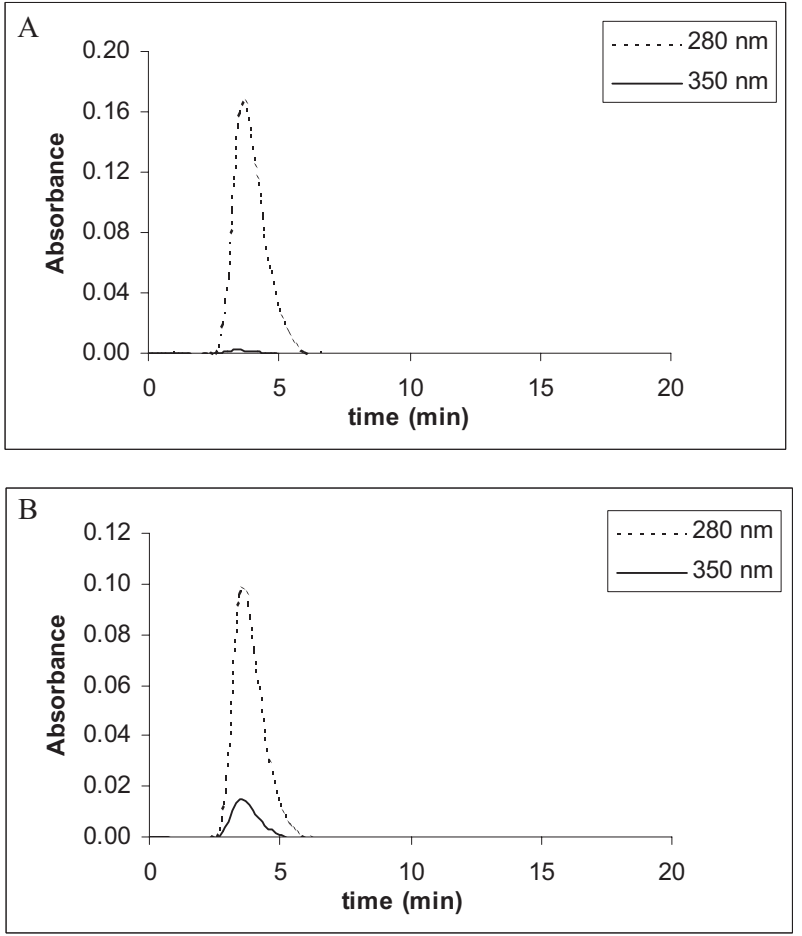

Figure 2. Gel filtration of: BSA (A) and BSA-RTX conjugate (B). Flow $0.3 \mathrm{ml} / \mathrm{min}$. Column: Sephadex G-25. Eluent: $0.05 \mathrm{M}$ phosphate buffer, $\mathrm{pH} 7$.
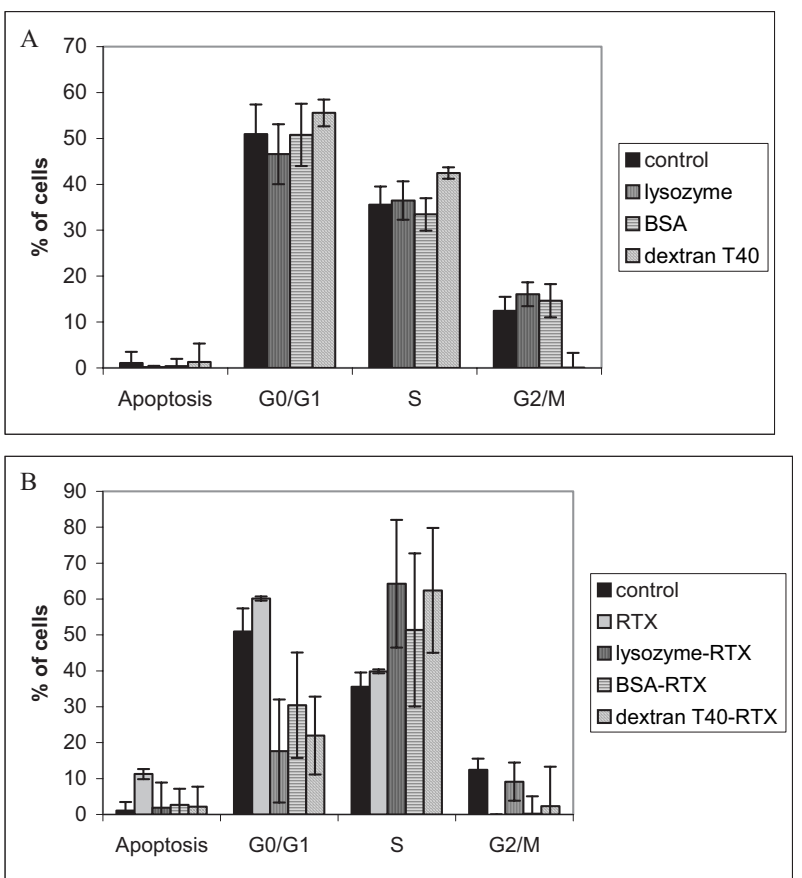

Figure 3. Influence of carriers (A) and RTX and its conjugates (B) on cell cycle and apoptosis of SW707 cell line.

span. RTX is a targeted thymidylate synthase inhibitor. The lack of effectiveness of the RTX conjugates in the experimental antineoplastic therapy can be due to high thymidine concentration in the animal models. Thymidine levels in rats and mice are by 100 - and 300-fold higher, respectively, than in humans (Li et al., 2003). Therefore, selective inhibition of thymidine biosynthe- 
sis in rodents might not exert a cytostatic effect on their tumors.

\section{Acknowledgements}

This work was supported by grant no. NN 302 098434 from the Ministry of Science and Higher Education (Poland).

\section{REFERENCES}

Bolling C, Graefe T, Lubbing C, Jankevicius F, Uktveris S, Cesas A, Meyer-Moldenhauer WH, Starkmann H, Weigel M, Burk K, Hanauske AR (2006) Phase II study of MTX-HSA in combination with cisplatin as first line treatment in patients with advanced or metastatic transitional cell carcinoma. Invest New Drugs 24: 521-527.

Boratynski J, Opolski A, Wietrzyk J, Gorski A, Radzikowski C (2000) Cytotoxic and antitumor effect of fibrinogen-methotrexate conjugate. Cancer Lett 148: 189-195.

Boratynski J (1984) Colorimetric method for the determination of ketoses using phenol-acetone-boric acid reagent (PABR). Anal Biochem 137: $528-532$

Budzynska R, Nevozhay D, Kanska U, Jagiello M, Opolski A, Wietrzyk J, Boratynski J (2007) Antitumor activity of mannan-methotrexate conjugate in vitro and in vivo. Oncol Res 16: 415-421.

Burger AM, Hartung G, Stehle G, Sinn H, Fiebig HH (2001) Pre-clinical evaluation of a methotrexate-albumin conjugate (MTX-HSA) in human tumor xenografts in vivo. Int I Cancer 92: 718-724.

Ghose T, Norvell ST, Guclu A, Cameron D, Bodurtha A, MacDonald AS (1972) Immunochemotherapy of cancer with chlorambucil carrying antibody. $\mathrm{Br} \mathrm{Med} J$ 3: 495-499.

Hartung G, Stehle G, Sinn H, Wunder A, Schrenk HH, Heeger S, Kranzle M, Edler L, Frei E, Fiebig HH, Heene DL, Maier-Borst W, Queisser W (1999) Phase I trial of methotrexate-albumin in a weekly intravenous bolus regimen in cancer patients. Phase I study group of the association for medical oncology of the German cancer society. Clin Cancer Res 5: 753-759.

Kanska U, Omar MS, Budzynska R, Nevozhay D, Jagiello M, Opolski A, Boratynski J (2005) Antileukemic activity of glycated fibrinogenmethotrexate conjugates. Anticancer Res 25: 2229-2234.

Kratz F (2008) Albumin as a drug carrier: design of prodrugs, drug conjugates and nanoparticles. I Control Release 132: 171-183.

Li KL, Clarke SJ, Rivory LP (2003) Quantitation of plasma thymidine by high-performance liquid chromatography - atmospheric pressure chemical ionization mass spectrometry and its application to pharmacodynamic studies in cancer patients. Anal Chim Acta 486: $51-61$.

Mathe G, Loc T, Bernard J (1958) Effect sur la leucemie 1210 de la souris d'une combinaison par diazotation d'A-methopterine et da $\gamma$-globulines de hamsters porteurs de cette leucmie par heterograffe. CR Acad Sci (Paris) 246: 1626-1630.

McGuire JJ (2003) Anticancer antifolates: current status and future directions. Curr Pharm Des 9: 2593-2613.

Myc A, Kukowska-Latallo J, Cao P, Swanson B, Battista J, Dunham T, Baker JR Jr (2010) Targeting the efficacy of a dendrimer-based nanotherapeutic in heterogeneous xenograft tumors in vivo. Anticancer Drugs 21: 186-192.

Nevozhay D, Budzynska R, Jagiello M, Kanska U, Omar MS, Opolski A, Wietrzyk J, Boratynski J, Opolski, A (2006a) The effect of the substitution level of some dextran-methotrexate conjugates on their antitumor activity in experimental cancer models. Anticancer Res 26: 2179-2186.

Nevozhay D, Budzynska R, Kanska U, Jagiello M, Omar MS, Boratynski J, Opolski A (2006b) Antitumor properties and toxicity of dextran-methotrexate conjugates are dependent on the molecular weight of the carrier. Anticancer Res 26: 1135-1143.

Nevozhay D, Kanska U, Budzynska R, Boratynski J (2007) Current status of research on conjugates and related drug delivery systems in the treatment of cancer and other diseases. Postepy Hig Med Dosw 61: $350-360$

Riebeseel K, Biedermann E, Loser R, Breiter N, Hanselmann R, Mulhaupt R, Unger C, Kratz F (2002) Polyethylene glycol conjugates of methotrexate varying in their molecular weight from MW 750 to MW 40000: synthesis, characterization, and structure-activity relationships in vitro and in vivo. Bioconjug Chem 13: 773-785.

Silverstein AM (1999) Paul Ehrlich's passion: the origins of his receptor. Immunol Cell Immunol 194: 213-221.

Skehan P, Storeng R, Scudiero D, Monks A, McMahn J, Vistica D, Warren JT, Bokesch H, Kenney S, Boyd MR (1990) New colorimetric cytotoxicity assay for anticancer-drug screening. I Natl Cancer Inst 82: 1107-1112.

Stehle G, Wunder A, Sinn H, Schrenk HH, Schutt S, Frei E, Hartung G, Maier-Borst W, Heene DL (1997) Pharmacokinetics of methotrexate-albumin conjugates in tumor-bearing rats. Anticancer Drugs 8: 835-844.

Stehle G, Wunder A, Schrenk HH, Hartung G, Heene DL, Sinn H (1999) Methotrexate-albumin conjugate causes tumor growth delay in Dunning R3327 HI prostate cancer-bearing rats. Anticancer Drugs 10: 405-411.

Wilson KS, Malfair Taylor SC (2009) Raltitrexed: optimism and reality. Expert Opin Drug Metab Toxicol 5: 1447-1454.

Wunder A, Stehle G, Schrenk HH, Hartung G, Heene DL, MaierBorst W, Sinn H (1998) Antitumor activity of methotrexate-albumin conjugates in rats bearing a Walker-256 carcinoma. Int I Cancer 76: 884-890.

Yousefi G, Foroutan SM, Zarghi A, Shafaati A (2010) Synthesis and characterization of methotrexate polyethylene glycol esters as a drug delivery system. Chem Pharm Bull (Tokyo) 58: 147-153. 